\title{
Unbiased Charged Circular CMUT Microphone: Lumped-Element Modeling and Performance
}

\author{
Hayrettin Köymen ${ }^{\circledR}$, Senior Member, IEEE, Abdullah Atalar, Fellow, IEEE, \\ Saadettin Güler, Itır Köymen, A. Sinan Taşdelen, and Aslı Ünlügedik
}

\begin{abstract}
An energy-consistent lumped-element equivalent circuit model for charged circular capacitive micromachined ultrasonic transducer (CMUT) cell is derived and presented. It is analytically shown and experimentally verified that a series dc voltage source at the electrical terminals is sufficient to model the charging in CMUT. A model-based method for determining this potential from impedance measurements at low bias voltages is presented. The model is validated experimentally using an airborne CMUT, which resonates at $103 \mathrm{kHz}$. Impedance measurements, reception measurements at resonance and offresonance, and the transient response of the CMUT are compared with the model predictions.
\end{abstract}

Index Terms-Airborne, charging, CMUT, electret, lumpedelement equivalent circuit model.

\section{INTRODUCTION}

C HARGING of CMUTs occur when the insulator layers between the two electrodes are polarized or accumulate trapped charges during production or operation. This affects the performance of CMUTs [1]-[6].

Materials such as silicon oxide $\left(\mathrm{SiO}_{2}\right)$, silicon nitride $\left(\mathrm{Si}_{3} \mathrm{~N}_{4}\right)$, and aluminum oxide $\left(\mathrm{Al}_{2} \mathrm{O}_{3}\right)$ are used as insulators in CMUTs. These dielectrics, particularly $\mathrm{SiO}_{2}$ and $\mathrm{Si}_{3} \mathrm{~N}_{4}$, are also widely used as electrets and are renowned for their superior properties. Charging in other micro-electromechanical systems (MEMS) devices such as RF switches is also scrutinized [7].

In this paper, we present analytical large- and smallsignal equivalent circuit models for the charged CMUT cell, which incorporates the behavior of capacitive transducers and electrets. The processes which cause charging in CMUTs, similar to electret formation for use in microphone technology, the similarity and differences of modeling of capacitive transducers and electret microphones are reviewed and discussed in this section. In Section II, charging effect modeling is explained and the equivalent circuit models are derived.

Manuscript received July 24, 2017; accepted November 10, 2017. Date of publication November 14, 2017; date of current version January 1, 2018. This work was supported by the Scientific and Technological Research Council of Turkey under Project 114E588. The work of A. Atalar was supported by the Turkish Academy of Sciences. (Corresponding author: Hayrettin Köymen.)

H. Köymen, A. Atalar, and I. Köymen are with the Electrical and Electronics Engineering Department, Bilkent University, 06800 Ankara, Turkey (e-mail: koymen@ee.bilkent.edu.tr).

S. Güler and A. S. Tasdelen are with the Bilkent University Acoustics and Underwater Technologies Research Center, Bilkent University, 06800 Ankara, Turkey.

A. Ünlügedik is with the Department of Mechanical Engineering, University of Texas at Austin, Austin, TX 78712 USA.

Digital Object Identifier 10.1109/TUFFC.2017.2773490
The experimental and simulation-based validation results are in Section III.

\section{A. Charging in CMUTs}

CMUTs are subject to charging at various stages of production. Techniques used for CMUT fabrication are also used for electret manufacturing [8]. For example, plasma-enhanced chemical vapor deposition is used in CMUT fabrication for insulating layer deposition $\left(\mathrm{SiO}_{2}, \mathrm{Si}_{3} \mathrm{~N}_{4}, \operatorname{orAl}_{2} \mathrm{O}_{3}\right)$. This process is known to induce charging to dielectrics. Another such technique is thermoelectric wafer bonding. While charging is an undesired outcome of CMUT fabrication, it is essential that electret insulators be charged. Using dc bias voltage also causes charging in CMUTs. There have been efforts to measure the amount of charging [3], [5], to mitigate the charging effect [1] or to analyze the charging in CMUTs [4]. Use of charged CMUTs for unbiased operation has also been successfully demonstrated [6], [9].

\section{B. Electret Microphones}

The effect of charging on CMUT performance can be better understood if the available knowledge on electret microphones is investigated. The theory underlying the electrets and electret microphones has been well studied since 1962 [10], [11]. The research on electrets is guided by the needs of electret microphones and mainly concentrated on charge trapping properties of polymers.

The works on inorganic electrets such as silicon oxide and nitride, which first appeared in 1983 [11], are reminiscent of charging effects in CMUTs. The potential of using electrets in micromachined microphones provided the motivation for extensive study of silicon-based dielectrics [12]-[18]. It is clear from these studies that the methods used to convert these insulators into electrets are also the methods used in CMUT production, and the production processes inherently result in charging.

\section{Analytical Modeling of Capacitive Transducers}

The first analytical model and small-signal equivalent circuit for capacitive transducers was proposed by Mason [19]. The total force acting on the clamped plate and the spatial average displacement (or velocity) are taken as across and through variables, respectively. The model is not energy consistent, since these two variables are not related through the energy in the structure. Although the model's prediction performance 
is impaired because of this issue, it provides a conceptual guidance. Hunt extended the model based on the parallel plate assumption [20], providing insight on the subtle issues of transduction and collapse.

Accurate modeling of capacitive and electret microphones gained importance in the 1980's after the MEMS microphones were proposed as a contending technology in the microphone market against electret microphones. We confine our interest in this paper to those contributions where the deflection profile of the clamped membrane is taken into account in the calculation of electrostatic energy, and the force and displacement are related thorough this energy.

Numerical modeling studies were carried out as early as 1975 [21], where the static deflection profile of the membrane is considered in electrostatic force calculation in an energy-based context.

van der Donk et al. [22] proposed the first analytical model in which the electrostatic force and the center displacement of the membrane are interrelated through the electrostatic energy in the microphone and the displacement profile.

Modeling research continued after the emergence of CMUTs as novel ultrasonic transducers. Even though the main issues in CMUT modeling are similar to that of capacitive microphones (including MEMS and electrets microphones), it appears that the earlier work aside from [19] and [20] were overlooked. There are two critical differences in CMUTs: the immersion medium and the gap pressure, which affect the transducer performance most radically.

1) Immersion Medium: CMUTs emerged primarily as ultrasonic transducers which are used in contact with or immersed in water and alike medium. The effect of medium loading in CMUTs is very significant as opposed to airborne microphones. The radiation impedance of air can either be ignored or modeled very simply for microphones, since the other losses in pressure compensated microphones overwhelm the radiation resistance. In waterborne applications, however, radiation impedance dominates CMUT performance.

2) Static Pressure in the Gap: All of the modeling efforts were essentially concerned with the performance prediction of airborne capacitive and electret microphones until CMUTs emerged. The gap in microphones is pressure compensated: the pressure inside the gap is maintained equally to the ambient static pressure by means of suitable passage of air and holes. The clamped plate is not deflected by static ambient pressure when the gap is pressure compensated. This allows the use of very low relative gap height in combination with very compliant membranes, even thin membranes made of polymers.

CMUTs are primarily vacuum gap devices and have airborne or immersed ultrasonic applications, rather than audio or other low-frequency applications. The clamped plate in the CMUT is depressed by the static ambient pressure even without any bias voltage. The collapse conditions are directly affected. The effects of ambient pressure on CMUTs must be considered in any design and optimization work.

Another reason which helped the separation of CMUT modeling work from that of other capacitive transducers is the availability of commercial finite-element analysis (FEA) packages. CMUTs emerged around the same time as FEA packages. Capacitive transducers, at least single cells, can be very successfully analyzed with FEA. FEA is capable of taking into account static depression, applied mechanics of the plate, etc. A paradigm shift was experienced in the early 1990's when FEA became the preferred analysis method as opposed to analytical modeling. FEA is an excellent tool for testing designs prior to production. Analytical modeling, on the other hand, provides insight for design, which is more difficult to achieve with FEA.

The behavior of CMUT cells [23]-[25] and arrays [26]-[29] has been widely studied using FEA. The differences between conventional and collapsed operation modes were analyzed in [30] and crosstalk in arrays using these modes were compared [31]. FEA is employed to design CMUT arrays for imaging [32], [33] and for airborne CMUTs [34], [35]. Boundary-element method is used to reduce the processing time particularly in the analysis of CMUT arrays [36]-[38]. These are only a few of many contributions concerning CMUT FEA modeling.

\section{CMUT Lumped-Element Modeling}

There had been efforts to derive more accurate analytical models for the CMUT by taking the deflection profile of the radiation plate into account [39], [40], the effects of layered radiation plates [41], [42] or effects like trapped gas in the gap [43]. An accurate lumped-element circuit model of a CMUT cell was proposed in [44]. The model is energy consistent, where as follows.

1) The lumped force and displacement variables related through the energy, where force and energy definitions included the ones presented in [22].

2) The effect of ambient pressure is analytically included.

3) The collapse phenomenon is analytically considered through static force equilibrium.

4) The transducer variables at the acoustic port and the acoustic field variables are consistent if spatial rms velocity is chosen as the through variable in the mechanical section.

5) The acoustic port is terminated by accurate radiation impedance at the radiating plate.

6) Large- and small-signal equivalent circuit models are provided, which are readily used in circuit simulators.

This model is extended to arrays of CMUT cells in [45], where the effect of the propagation medium on the performance is included through mutual impedances between the cells.

\section{E. CMUT Cell}

The geometry of a circular CMUT cell is depicted in Fig. 1, where $a, t_{m}, t_{g}$, and $t_{i}$ are the radius, the plate thickness, the gap height, and the insulator thickness, respectively. $x(r)$ defines the plate displacement profile [44]

$$
x(r)=x_{p}(t)\left(1-\frac{r^{2}}{a^{2}}\right)^{2} \quad r \leq a
$$




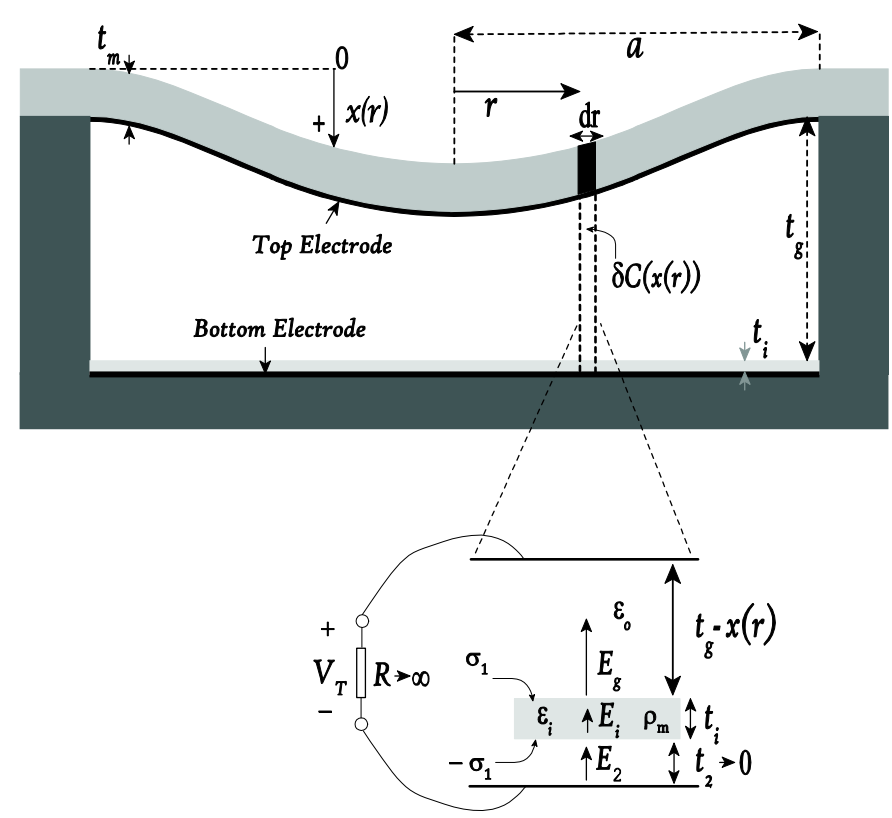

Fig. 1. Charged CMUT cell.

where $x_{p}(t)$ is the spatial peak displacement at the center. The clamped membrane assumes this profile in the frequency range, where the first vibration resonance of a clamped circular plate is dominant. This range extends up to about 1.9 times the first resonance frequency in water, where almost all of the applications are accommodated.

The geometry for the calculation of charging effects is also shown in Fig. 1. $\sigma_{1}$ and $\rho_{m}$ are the uniformly distributed surface and the volume charges in the insulator. $V_{T}$ is the voltage at the electrical terminals. $\varepsilon_{0}$ and $\varepsilon_{i}$ are the permittivity of the gap and the insulator material, respectively.

\section{Modeling Charged CMUT}

When the insulator dielectric layer is charged, both surface and volume charges can be induced in the material, depending on the production process. The insulator becomes a charged electret. The CMUT lumped-element model is rederived to include the electret effect.

The analysis of electrostatic fields in a gap-electretgap structure, with electrodes on both sides, is available in [46]-[48]. We assume both monopolar volume charges with uniformly distributed volume density $\rho_{m}$ and charges due to polarized dipoles are present in the electret. We model the trapped charges due to polarized dipoles as uniformly distributed equivalent surface charge densities $\sigma_{1}$ and $-\sigma_{1}$ at the two surfaces of the dielectric [47].

\section{A. Electret Equivalent Potential}

The induced charge on the top electrode of an electret microphone due to monopolar trapped charges is already derived in [48]. When [48, eq. (28)] is adopted for the CMUT geometry given in Fig. 1, the induced surface charge distribution on the top electrode due to monopolar trapped charges is obtained as

$$
\sigma_{\mathrm{sm}}(r, t)=-\varepsilon_{0} \frac{t_{i}}{2 \varepsilon_{i}} \frac{t_{i} \rho_{m}}{t_{\mathrm{ge}}-x(r, t)} \quad r \leq a
$$

when the external voltage $V_{T}$ is zero. $t_{\mathrm{ge}}$ in (2) is the effective gap height

$$
t_{\mathrm{ge}}=t_{g}+\frac{\varepsilon_{0}}{\varepsilon_{i}} t_{i}
$$

We derived the surface charge distribution due to trapped dipoles on the top electrode in Appendix A, following the approach given in [47]. For the CMUT geometry, one surface of the dielectric has an electrode, as depicted in Fig. 1. We initially assumed that there is a separation $t_{2}$ between the insulator and the bottom electrode [47]. We derived the prevailing electric fields with finite $t_{2}$. Then, we let the separation vanish, $t_{2}=0$, and calculate the surface charge density as

$$
\sigma_{\mathrm{sd}}(r, t)=-\varepsilon_{0} \frac{t_{i}}{\varepsilon_{i}} \frac{\sigma_{1}}{t_{\mathrm{ge}}-x(r, t)}
$$

when $V_{T}=0$.

When (2) and (4) are added to the charge produced by $V_{T}(t)$, we can express the total charge in a ring of radius $r$ and width $d r$ as

$$
\delta Q(r, t) \approx\left\{\varepsilon_{0} \frac{V_{T}(t)}{t_{\mathrm{ge}}-x(r, t)}+\sigma_{\mathrm{sd}}(r, t)+\sigma_{\mathrm{sm}}(r, t)\right\} 2 \pi r d r .
$$

This incremental charge can be written as

$$
\delta Q(r, t) \approx \varepsilon_{0} \frac{V_{T}-V_{E}}{t_{\mathrm{ge}}-x(r, t)} 2 \pi r d r
$$

by substituting (2) and (4) in (5), where

$$
V_{E}=t_{i} \frac{\sigma_{1}}{\varepsilon_{i}}+t_{i}^{2} \frac{\rho_{m}}{2 \varepsilon_{i}}
$$

is the effective electret potential.

The total charge on the top electrode is obtained upon integration over the surface of the CMUT cell [44]

$$
Q(t)=\left[V_{T}(t)-V_{E}\right] C_{0} g\left(\frac{x_{p}(t)}{t_{\mathrm{ge}}}\right)
$$

where $g(u)=\tanh ^{-1}(\sqrt{u}) / \sqrt{u}$ and $C_{0}=\varepsilon_{0} \pi a^{2} / t_{\mathrm{ge}}$. The charge on the bottom electrode, which is next to the insulator, is the same as given in (8) but with opposite polarity.

The instantaneous energy accumulated on the capacitance $W(t)$ when $V_{T}(t)$ is applied across the electrical terminals, is calculated as

$$
W(t)=\int_{0}^{Q(t)} v d Q
$$

where $d Q=C_{0} g(u) d v$ and $u=x_{P} / t_{\mathrm{ge}}$. We find

$$
W(t)=C_{0} g(u) \int_{0}^{V_{T}(t)-V_{E}} v d v=\frac{1}{2} C_{0} g(u)\left[V_{T}(t)-V_{E}\right]^{2} .
$$




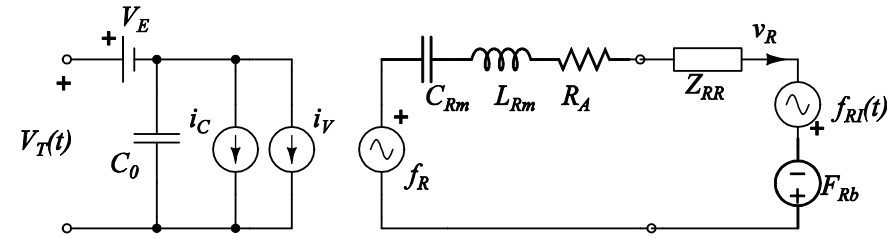

(a)

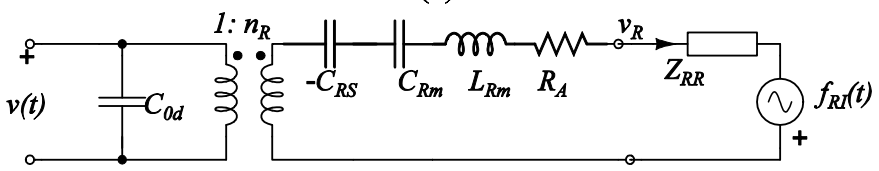

(b)

Fig. 2. Equivalent circuit model of charged CMUT. (a) Large signal. (b) Small signal.

\section{B. Equivalent Circuit}

It is clear from (10) that the energy due to the charge on the CMUT electrode is the same as that of the uncharged CMUT except a fixed additional equivalent bias of $V_{E}$, the equivalent electret potential, is imposed on the terminal voltage as a part of the model. The large-signal equivalent circuit model of the charged CMUT remains the same as the model of the uncharged CMUT discussed in [44] with a series voltage source, as depicted in Fig. 2(a). The model parameters for large- and small-signal equivalent circuits of CMUT are given in Appendix B for completeness.

It must be noted that the entire effect of charging on the lumped-element model is a series equivalent dc voltage source, if the trapped charge distribution is uniformly distributed or has radial symmetry. Using measurement-based determination of $V_{E}$ in the model is sufficient to consider all charging effect.

The equivalent circuit models presented in Fig. 2 are specific to CMUTs and cannot be used to model commercial electret microphones. Although the transduction model is the same for both devices, the mechanical side of electret microphones is very different compared to CMUTs. This paper is specifically concerned with charged CMUT cells. Hence the models used are not generalized to include the characteristics of electret microphones.

\section{Biasing Chart of Charged CMUT Cells}

Following the same approach in [44], the static force equilibrium for charged cells under a bias voltage of $V_{\mathrm{dc}}$ can be written as

$$
\sqrt{5} \frac{C_{0}\left[V_{T}(t)-V_{E}\right]^{2}}{2 t_{\mathrm{ge}}} g^{\prime}\left(\frac{X_{P}}{t_{\mathrm{ge}}}\right)+F_{\mathrm{Rb}}=\frac{X_{R}}{C_{\mathrm{Rm}}}
$$

where $X_{P}$ is the peak plate displacement under the bias voltage $V_{\mathrm{dc}}$. This yields

$$
\frac{V_{\mathrm{dc}}}{V_{r}}= \begin{cases}\sqrt{\frac{3\left(\frac{X_{P}}{t_{\mathrm{ge}}}-\frac{F_{\mathrm{Rb}}}{F_{\mathrm{Rg}}}\right)}{2 g^{\prime}\left(\frac{X_{P}}{t_{\mathrm{ge}}}\right)}+\frac{V_{E}}{V_{r}}} \quad \text { for } \frac{V_{\mathrm{dc}}}{V_{r}} \geq \frac{V_{E}}{V_{r}} \\ -\sqrt{\frac{3\left(\frac{X_{P}}{t_{\mathrm{ge}}}-\frac{F_{\mathrm{Rb}}}{F_{\mathrm{Rg}}}\right)}{2 g^{\prime}\left(\frac{X_{P}}{t_{\mathrm{ge}}}\right)}+\frac{V_{E}}{V_{r}}} \quad \text { for } \frac{V_{\mathrm{dc}}}{V_{r}}<\frac{V_{E}}{V_{r}}\end{cases}
$$

where $F_{\mathrm{Rg}}=t_{\mathrm{ge}} / \sqrt{5} C_{\mathrm{Rm}}$.

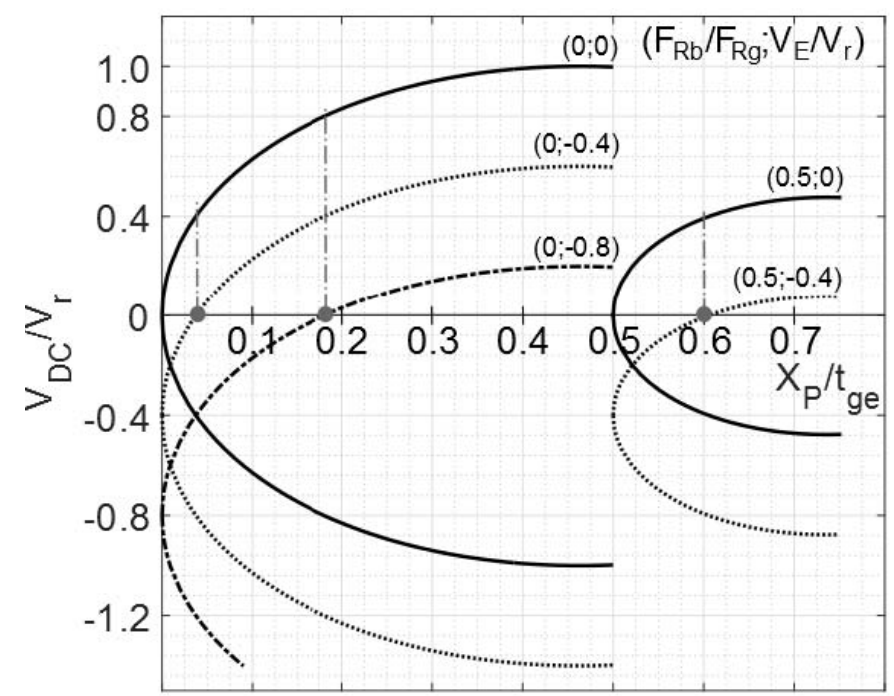

Fig. 3. $\mathrm{CBC}$ of charged CMUT for $F_{\mathrm{Rb}} / F_{\mathrm{Rg}}=0$ and $0.5 . V_{E} / V_{r}$ varies between 0 and -0.8 , plotted up to collapse threshold. Curves are labeled as $\left(F_{\mathrm{Rb}} / F_{\mathrm{Rg}} ; V_{E} / V_{r}\right)$. Vertical axis is flipped for positive $V_{E} / V_{r}$.

Equation (12) is plotted as the CMUT biasing chart (CBC) in Fig. 3 for negative $V_{E} / V_{r}$. The $\mathrm{CBC}$ is plotted for $\pm V_{\mathrm{dc}} / V_{r}$, because $\mathrm{CBC}$ is different for positive and negative bias in charged CMUT. CBC for uncharged CMUTs, $(0 ; 0)$ and $(0.5 ; 0)$, is also depicted for $\pm V_{\mathrm{dc}} / V_{r}$ for comparison, which are symmetric around $V_{\mathrm{dc}} / V_{r}=0$. If the normalized effective charging voltage $V_{E} / V_{r}$ is positive, Fig. 3 must be flipped vertically.

When the polarity of the bias voltage is appropriate, $V_{E}$ reinforces the bias and larger displacement is achieved for a relatively low $V_{\mathrm{dc}} / V_{r}$. For example, collapse displacement is reached at $V_{\mathrm{dc}} / V_{r}=1$ in vacuum when $V_{E}$ is zero, but $V_{\mathrm{dc}} / V_{r} \approx 0.2$ is sufficient for collapse when $V_{E} / V_{r}=-0.8$.

The turns ratio can be significantly large for zero bias if $V_{E} / V_{r}$ is large, as (32) (Appendix B) indicates. The operating point for the small-signal model at zero external bias is the same as that of $80 \%$ bias when $V_{E} / V_{r}=-0.8$ (or +0.8 ).

\section{VALidATION OF THE MOdEL}

\section{A. Materials}

The model is validated experimentally using airborne CMUT cells. Validation is performed in two steps. First, the effective electret voltage $V_{E}$ is determined using conductance peak measurements in the model based method presented in this paper. This method is described in Section III-B. Then, using the model with estimated $V_{E}$, the CMUT cell is used as a microphone in Section III-C. The sensitivity and transient measurements while the CMUT cell operates at resonance and at lower frequencies are compared with the model predictions.

The CMUTs, from the batch described in [50], have $\mathrm{SiO}$ insulator layers and are produced using anodic wafer bonding. ${ }^{1}$ Because of processes involved in the production, the insulator layer is charged. The amount of charging cannot be measured directly but secondary measurement methods must be used [9] in order to estimate it. We describe a methodology

\footnotetext{
${ }^{1}$ Applied Microengineering Ltd., Oxfordshire, UK.
} 


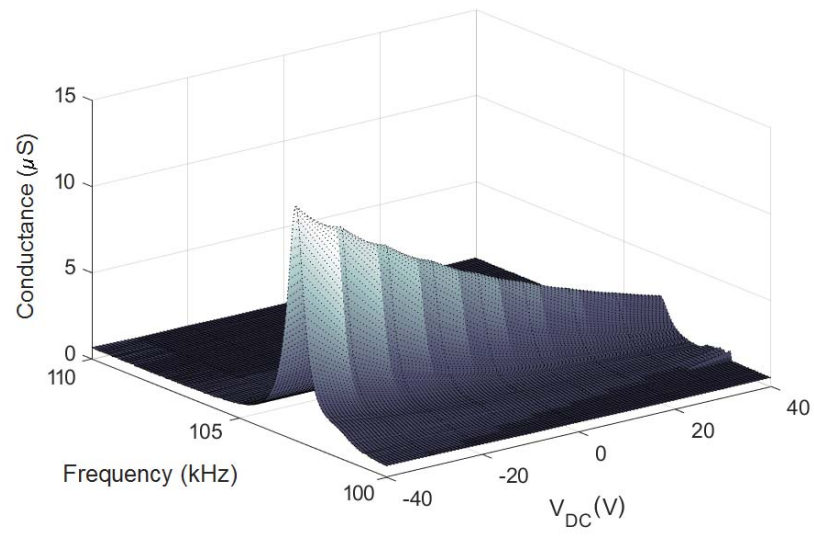

(a)

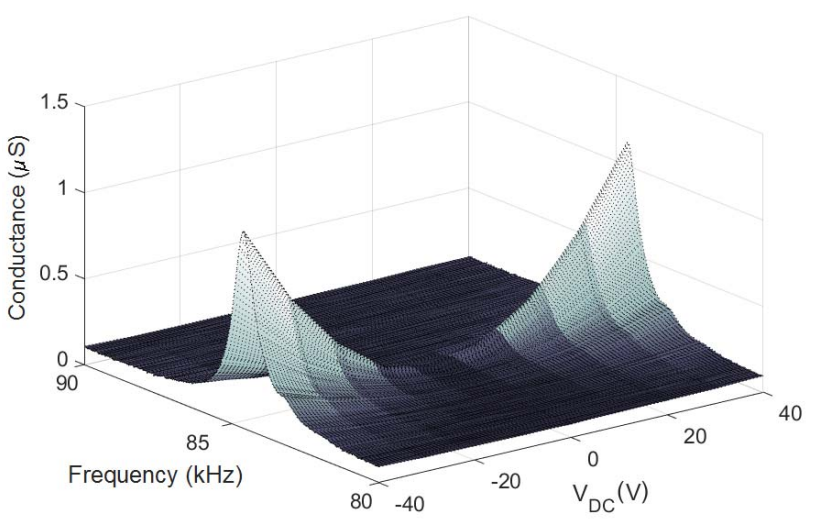

(b)

Fig. 4. Variation of conductance spectrum with respect to bias voltage measured in two different CMUT cells versus frequency and bias voltage. (a) Charged. (b) Uncharged.

here, where the presented model is used both to estimate the effective electret voltage due to charging and to subsequently assess the performance of the CMUT.

A charged CMUT cell can have transduction when it is not biased and therefore exhibit an impedance variation. The electrical conductance of a charged and an uncharged airborne cell are depicted in Fig. 4. Although most of the cells on the same wafer exhibit charging right after production, we observed that the trapped charge is removed when the CMUT is driven by relatively large amplitude continuous-wave (CW) ac voltage without any bias. Maximum drive voltage amplitudes were in the range $60-100 \mathrm{~V}, 10 \%-20 \%$ of $V_{r}$, for various CMUTs, and the frequencies were set to the half of the mechanical resonance frequency of the respective CMUT cells, as described in [50]. When driven in this mode, the plate vibrates at resonance frequency and its center spans the entire gap. The CMUT in Fig. 4(b) is uncharged most probably for this reason, whereas the CMUT depicted in Fig. 4(a) was not subject to such an electrical drive. The variation of conductance with respect to frequency is plotted as the bias voltage is swept between $\pm 40 \mathrm{~V}$. The peaking conductance at resonance is a function of bias voltage as well as charging. The electrical impedance measurements are made using an impedance analyzer. $^{2}$

\footnotetext{
${ }^{2}$ HP 4194A, Hewlett-Packard, Palo Alto, CA, USA.
}

TABLE I

Nominal Material Properties ANd Physical DIMENSIONS OF THE CMUT CELL

\begin{tabular}{|l|c|c|c|}
\hline Plate radius & $a$ & 1.7 & $\mathrm{~mm}$ \\
\hline Plate thickness & $t_{m}$ & 80 & $\mu \mathrm{m}$ \\
\hline Effective gap height & $t_{g e}$ & 6.4 & $\mu \mathrm{m}$ \\
\hline Insulating layer thickness & $t_{i}$ & 1.0 & $\mu \mathrm{m}$ \\
\hline Collapse voltage in vacuum & $V_{r}$ & 810 & $\mathrm{~V}$ \\
\hline Normalized static mechanical force & $F_{R b} / F_{R g}$ & $0.28^{*}$ & \\
\hline Collapse voltage for given $\mathrm{F}_{\mathrm{b}} / \mathrm{F}_{\mathrm{g}}$ & $V_{c}$ & 570 & $\mathrm{~V}$ \\
\hline Young's Modulus of Silicon & $Y_{0}$ & 148 & $\mathrm{GPa}$ \\
\hline Poisson's Ratio of Silicon & $\sigma$ & 0.17 & \\
\hline Density of Silicon & $\rho$ & 2370 & $\mathrm{~kg} / \mathrm{m}^{3}$ \\
\hline Intrinsic impedance of air & & 420 & Rayls \\
\hline
\end{tabular}

The most prominent and direct difference between the charged and uncharged CMUTs is in the peak conductance value, as illustrated in Fig. 4. In order that any transduction can occur and a conductance is observed in an uncharged CMUT, a bias voltage of either polarity is required. Fig. 4(b) demonstrates that at $V_{\mathrm{dc}}=0$ the electrical conductance peak at resonance is zero. This is due to the fact that at $V_{\mathrm{dc}}=0$ the turns ratio in the small-signal equivalent circuit is zero as well. However, when the cell is charged, the turns ratio given by (32) is not zero due to finite effective electret voltage and a finite conductance peak is observed. A trend can be clearly deduced from Fig. 4(a) that the conductance peak decreases to a minimum for increasing values of positive bias.

\section{B. Impedance Measurements and Losses in CMUT Cell}

A charged CMUT cell resonating near $103.4 \mathrm{kHz}$ in air is used in model validation. Fig. 4(a) depicts the conductance graph of this CMUT, whose material properties and physical dimensions are given in Table I. The CMUT exhibits a peak conductance, varying between $13.75 \mu \mathrm{S}$ at $-40 \mathrm{~V}$ and $103.075-\mathrm{kHz}$ external bias and $2.69 \mu \mathrm{S}$ at $+40 \mathrm{~V}$ and $103.75 \mathrm{kHz}$. As the bias voltage is increased, the resonance frequency increases very slightly while the turns ratio is lowered. The quality factor of resonance is about 160 at $-40 \mathrm{~V}$. Both the peak conductance and quality factor measurements differ from the model prediction.

It is best to carry out airborne measurements to assess the validity of the model rather than waterborne measurements. The performance of the device is primarily determined by its own mechanical and electrical properties in air, where the effect of immersion medium is minimal. Certain loss mechanisms which are insignificant in waterborne operation manifest themselves more in airborne operation. In particular, the loss to substrate, loss in gap due to gas compression and radiation plate loss has been considered as follows.

The model presented in this paper assumes that the substrate is rigid and that there is no energy loss it. It is shown in [52] that any transfer of energy to the substrate through the gap appears as parallel impedance at the node between $-C_{\mathrm{RS}}$ and $C_{\mathrm{Rm}}$. The energy lost to the substrate is expected to be very low. 


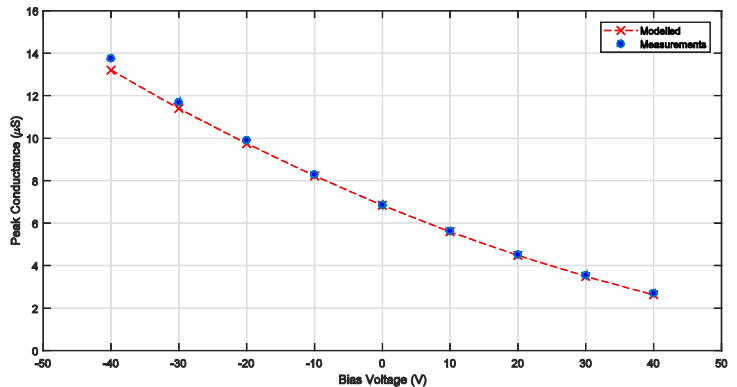

Fig. 5. Measured and model-based estimation of peak conductance of the CMUT cell versus bias voltage, with $Y_{0}=144.1 \mathrm{GPa}, t_{\mathrm{ge}}=6.53 \mu \mathrm{m}$, and $V_{E}=106.1 \mathrm{~V}$.

Another loss mechanism can be due to the losses that take place in the gap, such as the compression of the gas in the gap. There is nitrogen which has about 0.12 SAP partial pressure in the gap. The compliance of the gas in the gap is ignored in the model since it is in series with the plate compliance, which is much smaller.

The losses take place in the radiation plate, or by means of the plate, due to the internal frictional loss in the plate material or energy coupled to the surface or to the substrate bulk at the rim. This loss mechanism appears as a series term in lumpedelement model and affects both the conductance level and the quality factor of resonance. It has been observed that a single series resistance $R_{A}$ in Fig. 2, adequately models this effect in an ad hoc manner, in the vicinity of resonance.

The comparison of measured quality factor with the one predicted by the model alleviates the ambiguity in the relation of $V_{E}$ estimation and mechanical loss. The quality factor of this cell is estimated as 230 in air if the radiation resistance was the only resistive component in the mechanical section. The measured quality factor is about 160 . The difference can be accounted for if a series loss of $44 \%$ of the radiation resistance is assumed. This series resistance corresponds to $-3.2 \mathrm{~dB}$ loss in airborne transmission, and Fig. 2 is comparable to the loss in other cells in the same batch, which are reported in [50].

The loss tangent of the dielectric reflected to the total capacitance was determined as 0.0077 for this wafer in [50]. The baseline corrections on the conductance values are made using the susceptance data, which had little effect at frequencies near resonance. The measured peak conductance of each CMUT is plotted against the bias voltage in Fig. 5.

\section{Model-Based Characterization}

The mechanical resonance frequency $f_{m}$ and the series branch resonance frequency $f_{s}$ are discussed in Appendix B. The expressions given in (38) and (39) are accurate for the series branch resonance frequency of an airborne CMUT cell, because the radiation reactance is insignificant compared to the mass of the plate.

The bias voltage and the effective gap height are also primarily effective on the low-frequency open-circuit received voltage (OCRV) sensitivity of the CMUT [53]. If the effective gap height is varied, the resonance frequency is affected as well as the sensitivity at a given bias voltage.
The peak conductance is determined by the radiation resistance at resonance, the losses in the cell and the turns ratio. The nondimensional frequency parameter $k a$, the product of wavenumber and radius, of this CMUT cell is 3.3 at resonance, where the radiation resistance is 1.3 times the plane wave impedance [44]. Hence, the total resistance at resonance, the radiation and the loss resistance discussed in Section III-B, becomes 1.87 times the plane wave impedance in air.

The total mechanical resistance at resonance is transformed to the electrical port by means of the turns ratio $n_{R}$ given in (34). The series resonance frequency and the peak conductance measurements from -40 to $40 \mathrm{~V}$ external bias $V_{\mathrm{dc}}$ are used to validate the model using (30), (32), and (38). Equations (28) and (29) are substituted in (32), in order to relate the turns ratio to the dimensions an material properties. Furthermore, (34) and $F_{\mathrm{Rb}} / F_{\mathrm{Rg}}$ are used to determine the static bias conditions. The model predictions are fitted to measurement data of resonance frequency and the peak conductance, where $Y_{0}, t_{\mathrm{ge}}$, and $V_{E}$ are considered unknowns. The leastsquares error is minimized as unknown variables are varied, and other dimensions $a$ and $t_{m}$, the material properties $\rho_{m}$ and $\sigma$, and other parameters $\varepsilon_{0}$ and $P_{0}$ are kept at the nominal values in Table I.

The average rms errors of model predictions were $0.1 \%$ and $1.94 \%$ for the frequency and the conductance, respectively. $Y_{0}, t_{\mathrm{ge}}$, and $V_{E}$ are determined as $144.1 \mathrm{GPa}, 6.53 \mu \mathrm{m}$, and $106.1 \mathrm{~V}$, respectively. The prediction of the small-signal model is shown in Fig. 5.

Increasing the number of unknowns in the model fitting does not improve the accuracy of the fit. The dimensions, radius, thickness, and effective gap height, and $Y_{0} /\left(1-\sigma^{2}\right)$ appear in only two different combinations in all of the expressions used in the calculation of the turns ratio and the series resonance frequency. When the number of unknowns is increased, the problem becomes ill posed.

The peak conductance values are measured three times: 1) two years after the production but before any measurement; 2) one month after the first set of experiments; and 3) five months later, after the final set of experiments. The peak conductance measurements remained within the measurement accuracy. The agreement between the three sets of measurements indicates that the charging in the cell did not change. Final set of measurements is depicted in Fig. 5 together with model predictions.

This approach allows the measurement of effective electret voltage due to charging using impedance measurements at low external bias voltages.

\section{Receiver Measurements}

1) Measurement Setup: The sensitivity of the cell as a microphone is measured at the resonance frequency and at lower frequencies. The CMUT is insonified using two different wideband airborne transmitters, a piezoelectric tweeter, ${ }^{3}$ and an array of four capacitive elements ${ }^{4}$ between 30 and $110 \mathrm{kHz}$,

\footnotetext{
${ }^{3}$ ES105 Tweeter System, Murata Manufacturing Co. Ltd., Japan.

${ }^{4}$ Series 600 Capacitive transducer, SensComp Inc., Livonia, MI, USA.
} 


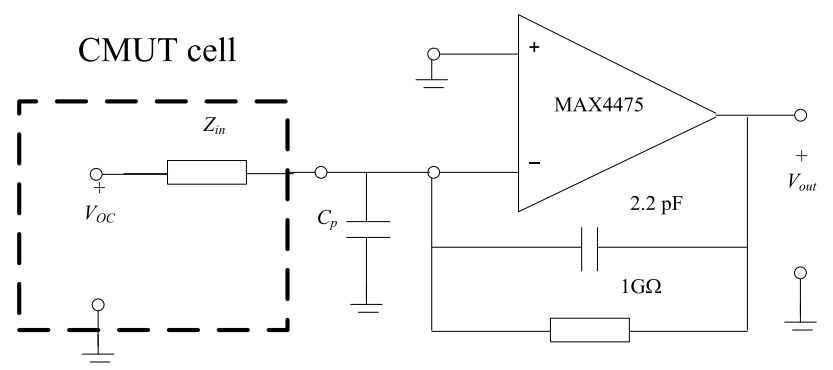

(a)

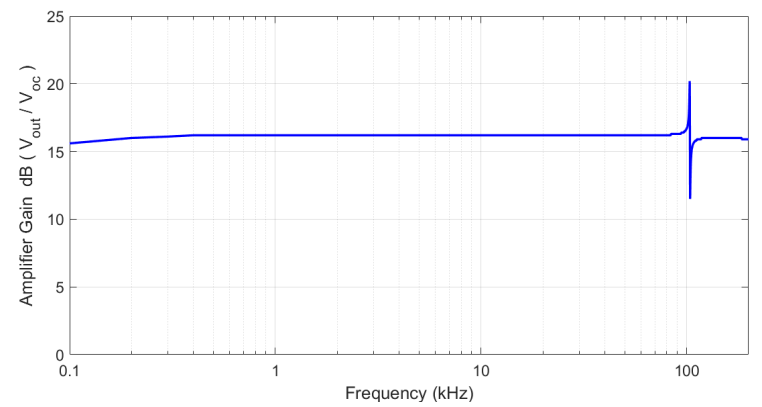

(b)

Fig. 6. (a) Integrating amplifier and CMUT cell model. (b) Gain of the preamplifier when CMUT is connected to the input, $V_{\text {out }} / V_{\mathrm{OC}}(\mathrm{dB})$ (gain $16.2 \mathrm{~dB}$ ).

which are driven by a signal generator ${ }^{5}$ and a power amplifier. $^{6}$

2) Preamplification: There are two options for preamplification of received signals in CMUT applications: 1) voltage amplification and 2) transimpedance amplifier. When voltage amplification is used, the received signal suffers the attenuation due to parasitic capacitance $C_{p}$ parallel to the electrical port. The transimpedance amplifier with capacitive feedback, i.e., integrating amplifier configuration, is particularly useful to minimize the effect of these parasitics in lower frequency OFF-resonance operation, where the CMUT impedance is predominantly capacitive. As the frequency is increased, the virtual ground effect is impaired and parasitic capacitance becomes more effective.

A low-noise OPAMP preamplifier is designed and mounted next to the CMUT to avoid cable losses and any interference. Preamplifier is build using an OPAMP ${ }^{7}$ with $2.2 \mathrm{pF}$ and $1 \mathrm{G}$ in parallel as feedback impedance, and the CMUT is connected directly to the inverting input, as shown in Fig. 6(a). The noninverting input of the OPAMP is connected to common. The input voltage $V_{\mathrm{OC}}$ is the ideal OCRV of the CMUT. The input impedance $Z_{\text {in }}$ is essentially the input capacitance of the CMUT

$$
C_{0 d}+n_{R}^{2} \frac{C_{\mathrm{Rm}} C_{\mathrm{RS}}}{C_{\mathrm{Rm}}-C_{\mathrm{RS}}}
$$

in the OFF-resonance frequency range, which is estimated as $14.3 \mathrm{pF}$. Hence the preamplifier provides a fixed voltage gain of $16.2 \mathrm{~dB}$ to $V_{\mathrm{OC}}$, which is equivalent to the ratio of

\footnotetext{
${ }^{5}$ Agilent Technologies 33250A, Santa Clara, CA, USA.

${ }^{6}$ Krohn-Hite 7500, Krohn-Hite Corporation, Brockton, MA, USA.

${ }^{7}$ MAX4475ASA, Maxim Integrated, San Jose, CA, USA.
}

this input capacitance and the feedback capacitance $2.2 \mathrm{pF}$. For the given OPAMP, the effect of parasitics is decreased by about $60 \mathrm{~dB}$ at $10 \mathrm{kHz}$ and $40 \mathrm{~dB}$ at $100 \mathrm{kHz}$.

This constant gain is not applicable near resonance since $Z_{\text {in }}$ is no longer purely capacitive but approaches to the parallel combination of radiation resistance and clamp capacitance. The circuit depicted in Fig. 6(a) is simulated using the employed OPAMP and the model in a circuit simulator to calculate the gain imposed on $V_{\mathrm{OC}}$ at every frequency, and plotted in Fig. 6(b).

The equivalent circuit component values are obtained using the data given in Table I on $a, t m, \sigma$ and the impedance of air. The values of $Y_{0}, t_{\mathrm{ge}}$, and $V_{E}$ are as obtained in Section III-C, and $F_{\mathrm{Rb}} / F_{\mathrm{Rg}}, V_{C}$, and $V_{r}$ are recalculated. These variables are used in the expressions provided in Appendix B, to determine the following equivalent circuit parameter values: $C_{0}=12.31 \mathrm{pF}, C_{0 d}=13.74 \mathrm{pF}, C_{\mathrm{RS}}=149.6 \mu \mathrm{m} / \mathrm{Nt}$, $C_{\mathrm{Rm}}=1.362 \mu \mathrm{m} / \mathrm{Nt}, L_{\mathrm{Rm}}=1.721 \mu \mathrm{mg}$, and $n_{R}=$ $222.9 \mu \mathrm{Nt} / \mathrm{V}$. Radiation resistance and reactance are functions of frequency and calculated as $R_{\mathrm{RR}}(f)=0.0038 R_{1}(\mathrm{ka}) \mathrm{kg} / \mathrm{s}$ and $X_{\mathrm{RR}}(f)=0.0038 X_{1}(k a) \mathrm{kg} / \mathrm{s}$, where $R_{1}(k a)$ and $X_{1}(k a)$ are given in [44]. The wavenumber $k$ is $2 \pi f / c_{0}$, where $c_{0}$ is the velocity of sound in air $340 \mathrm{~m} / \mathrm{s}$.

The incident acoustic pressure level is monitored using a pressure-field microphone ${ }^{8}$ mounted on a preamplifier ${ }^{9}$ using an adaptor. ${ }^{10}$ The microphone is polarized by a power supply. ${ }^{11}$ The sensitivity of the microphone subsystem is $-66.9 \mathrm{~dB} / /(\mathrm{V} / \mathrm{Pa})$. The tolerance in the sensitivity of the measurement microphone is specified as $\pm 2 \mathrm{~dB}$.

The CMUT cell, which is on the undiced in wafer, and the measurement microphone (protection grid removed) are mounted on a planar rigid hardboard baffle. This is the recommended configuration for the measurement microphone to be used as pressure microphone [51]. The separation between the microphone and CMUT cell was about $10 \mathrm{~cm}$.

Both $\mathrm{CW}$ and pitch-catch measurements are made. $\mathrm{CW}$ measurements are made using a spectrum analyzer. ${ }^{12}$ The pitch-catch mode measurements are performed with a pulse of about 3-ms duration. The steady-state response is ensured with this pulse duration at all frequencies. More than $1.15-\mathrm{m}$ separation is maintained between the projector and the receivers during measurements, which provided more than the range required by 3 -ms travel time. Apart from eliminating the interference, this separation also provided a reasonably uniform acoustic field on the measurement plane. Both the CMUT signal at preamplifier and the $\mathrm{B} \& \mathrm{~K}$ microphone outputs are measured and recorded using an oscilloscope, ${ }^{13}$ at every measurement frequency.

3) Sensitivity at Resonance: The amplified output voltage is corrected for the gain of the preamplifier, depicted in Fig. 6(b), and normalized to the incident pressure amplitude to estimate the OCRV sensitivity. The incident pressure ampli-

\footnotetext{
${ }^{8}$ B\&K 4138, Bruel and Kjær, Nærum, Denmark.

${ }^{9}$ B\&K 2633, Bruel and Kjær.

${ }^{10}$ B\&K UA 160, Bruel and Kjær.

${ }^{11}$ B\&K2807, Bruel and Kjær.

${ }^{12}$ HP8590L, Agilent Technologies, Santa Clara, CA, USA.

${ }^{13}$ DSO1002A, Agilent Technologies, Santa Clara, CA, USA.
} 


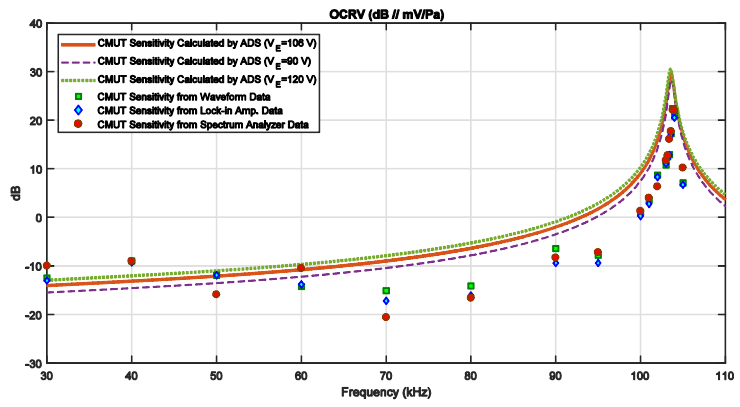

Fig. 7. OCRV sensitivity measurements of charged CMUT at resonance and OFF-resonance using piezoelectric tweeters projector and three different receiving schemes: 1) pulse amplitude (oscilloscope); 2) pulse amplitude using lock-in amplifier; and 3) CW using spectrum analyzer; together with model prediction

tude is estimated by the measurements obtained from BK4138. For example, the $\mathrm{CW}$ measurement is normalized by the output of the spectrum analyzer measurements obtained from the measurement microphone. Measured sensitivity is plotted against frequency in Fig. 7, where the piezoelectric tweeter is used for insonification. The prediction of the model is also shown in Fig. 7 as the solid line for $V_{E}=106 \mathrm{~V}$. Model predictions for $V_{E}=90$ and $120 \mathrm{~V}$ are also plotted for comparison.

Prior to every measurement, we aligned the projector, receivers, CMUT, and the measurement microphone by maximizing the received amplitude, so that the separation between the two receivers did not impair the measurement. It was observed, however, that the nonuniformity of the insonification on the surface of measurement caused a finite variance in measured values. It should be noted that the nonuniformity is also dependent on the frequency.

The same set of measurements is also repeated using projector made of an array of four capacitive transmitter elements. Similar sensitivity variation is obtained except with a sensitivity difference of \pm 2 to $\pm 4 \mathrm{~dB}$ at different frequencies.

The model predicts higher sensitivity at the frequency range above $50 \mathrm{kHz}$. Model predictions are lower at lower frequencies. We first note that acoustic measurements reported in this paper are absolute measurements and not relative measurements. This kind of difference is also observed in transmitted pressure measurements of the CMUTs at the mechanical resonance frequency in the same batch [50]. It is an established fact that absolute pressure measurements in air are always prone to measurement errors compared to waterborne measurements. The wideband measurements in air, as in this case, are affected by the measurement environment differently at different frequencies.

The diffraction effects due to the large aperture size of the projectors and the separation between the measurement microphone and the CMUT cell are liable to cause measurement errors. The separation between the receivers cannot be decreased to a fraction of a wavelength, because of the size of the wafer. The diffraction effects are very pronounced due to the small wavelength $(1 \mathrm{~cm}$ at $34 \mathrm{kHz}$ and $3.4 \mathrm{~mm}$ at $100 \mathrm{kHz}$ ).

4) Time-Domain Response: The wafer is completely shielded with copper foil such that only CMUT cell aperture

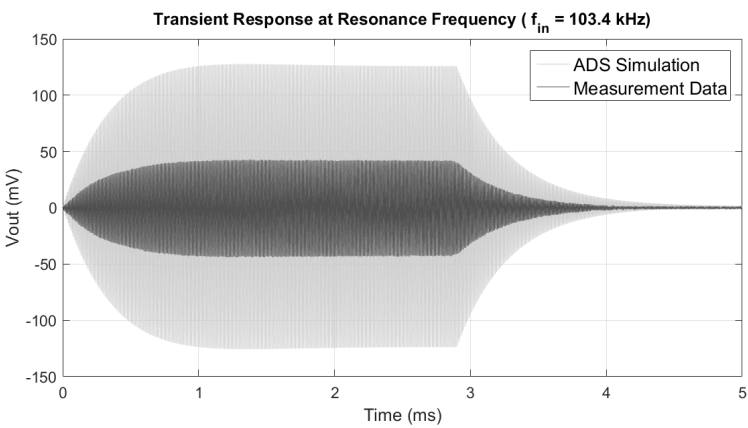

(a)

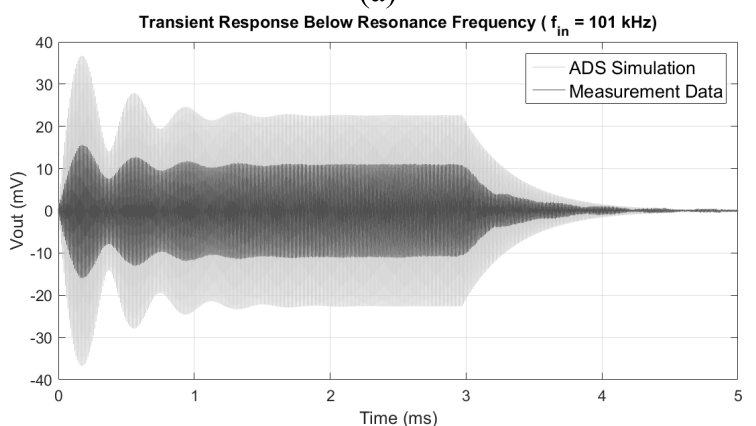

(b)

Fig. 8. CMUT cell response to a long pulse: measured response and simulation prediction at and near the resonance frequency. (a) $103.4 \mathrm{kHz}$. (b) $100 \mathrm{kHz}$.

is exposed during the measurements and any interference is avoided.

The CMUT cell is modeled using advanced design systems $(\mathrm{ADS})^{14}$ and the received voltage pulse is estimated. The series loss calculated in Section III-B2 is included in the model. The input signal to the model is a pressure pulse, the amplitude of which is obtained from the measurement microphone. The model prediction at resonance and the measured signal are depicted in Fig. 8(a).

The temporal response of the model displays a perfect match to the measured signal. The exponential rise and the decaying tail are estimated accurately by the model. The effect of very high quality of resonance is clearly visible in Fig. 8(b), where slightly OFF-resonance performance of the model is depicted at $105 \mathrm{kHz}$. The transient response during the pressure pulse and the tail is very accurately predicted by the model.

\section{CONCLUSION}

The existing equivalent circuit model of a CMUT presented in [43] is extended to derive a model for a charged CMUT. In the charged CMUT model, the effective electret voltage appears as a series dc voltage at the device terminals.

The model is validated experimentally. First, the peak conductance of a charged CMUT at resonance frequency is estimated using the model. The conductance of the charged CMUT is correctly estimated only when the correct effective equivalent electret voltage is assumed in the model. Fig. 5 demonstrates that this model-based approach is a reliable

\footnotetext{
${ }^{14}$ Advanced Design Systems, Keysight Technologies, Santa Rosa, CA, USA.
} 
method for estimating the equivalent electret voltage from impedance measurements using low bias voltage.

The sensitivity of the CMUT as a microphone is measured and compared to the model estimate as the second step. The effective electret voltage determined in the first step is employed in the model for this estimate.

Finally, the transient response of the CMUT is measured and it is observed that the temporal variation is accurately predicted by the model.

\section{APPENDIX A}

We model the trapped dipole charges as surface charge distributions on two surfaces of the insulator [46], [47]. The generated electric field is related to the charge distributions as

$$
\begin{aligned}
& +\varepsilon_{0} E_{g}-\varepsilon_{i} E_{i}=\sigma_{1} \\
& +\varepsilon_{i} E_{i}-\varepsilon_{0} E_{2}=-\sigma_{1}
\end{aligned}
$$

at the surface of the insulator. Also Kirchhoff's voltage law can be written as

$$
V_{T}+\left(t_{g}-x(r)\right) E_{g}+t_{i} E_{i}+t_{2} E_{2}=0 .
$$

The electric fields in the CMUT are determined by solving these three equations simultaneously

$$
\begin{aligned}
E_{2} & =-\frac{V_{T}}{t_{\mathrm{ge}}-x(r)}+\frac{1}{t_{\mathrm{ge}}-x(r)} \frac{t_{i}}{\varepsilon_{i}} \sigma_{1} \\
E_{i} & =-\frac{\varepsilon_{0}}{\varepsilon_{i}} \frac{V_{T}}{t_{\mathrm{ge}}-x(r)}-\frac{\sigma_{1}}{\varepsilon_{i}}+\frac{1}{t_{\mathrm{ge}}-x(r)} \frac{t_{i}}{\varepsilon_{i}} \frac{\varepsilon_{0}}{\varepsilon_{i}} \sigma_{1} \\
E_{g} & =-\frac{V_{T}}{t_{\mathrm{ge}}-x(r)}+\frac{1}{t_{\mathrm{ge}}-x(r)} \frac{t_{i}}{\varepsilon_{i}} \sigma_{1}
\end{aligned}
$$

where

$$
t_{\mathrm{ge}}=t_{g}+t_{i} \frac{\varepsilon_{0}}{\varepsilon_{i}}+t_{2}
$$

Surface charge density on membrane electrode (top) is determined using $E_{g}$

$$
\begin{aligned}
-\varepsilon_{0} E_{g} & =\sigma_{\mathrm{st}}(r) \\
\sigma_{\mathrm{st}}(r) & =\varepsilon_{0} \frac{V_{T}}{t_{\mathrm{ge}}-x(r)}-\varepsilon_{0} \frac{1}{t_{\mathrm{ge}}-x(r)} t_{i} \frac{\sigma_{1}}{\varepsilon_{i}} \\
& =\varepsilon_{0} \frac{V_{T}-t_{i} \frac{\sigma_{1}}{\varepsilon_{i}}}{t_{\mathrm{ge}}-x(r)} t_{2}=0 .
\end{aligned}
$$

Letting

$$
V_{E}=t_{i} \frac{\sigma_{1}}{\varepsilon_{i}}
$$

we find

$$
\sigma_{s t}(r)=\varepsilon_{0} \frac{V_{T}-V_{E}}{t_{\mathrm{ge}}-x(r)} .
$$

The surface charge on the bottom electrode is found as

$$
\begin{aligned}
\varepsilon_{0} E_{2} & =\sigma_{\mathrm{sb}}(r) \\
\sigma_{\mathrm{sb}}(r) & =-\varepsilon_{0} \frac{V_{T}}{t_{\mathrm{ge}}-x(r)}+\varepsilon_{0} \frac{1}{t_{\mathrm{ge}}-x(r)} \frac{t_{i}}{\varepsilon_{i}} \sigma_{1}=-\sigma_{\mathrm{st}}(r)
\end{aligned}
$$

when we let $t_{2}=0$.

\section{APPENDIX B}

\section{A. Large-Signal Equivalent Circuit}

Referring to Fig. 2(a), the two controlled current sources at the electrical side are

$$
i_{C}(t)=C_{0}\left[g\left(\frac{x_{P}(t)}{t_{\mathrm{ge}}}\right)-1\right] \frac{d V_{T}(t)}{d t}
$$

and

$$
i_{V}(t)=\sqrt{5} \frac{C_{0}}{t_{\mathrm{ge}}}\left[V_{T}(t)-V_{E}\right] g^{\prime}\left(\frac{x_{P}(t)}{t_{\mathrm{ge}}}\right) v_{R}(t)
$$

where

$$
{ }_{\varepsilon} C_{0}=\varepsilon_{0} \frac{\pi a^{2}}{t_{\mathrm{ge}}}
$$

is the clamped capacitance, $v_{R}(t)=(1 / \sqrt{5}) d x_{P}(t) / d t$ is the rms dynamic plate velocity [44] and $g^{\prime}(u)=(1 /(1-u)-$ $g(u)) /(2 u)$. The rms transduction force $f_{R}(t)$ is controlled by $V_{T}(t)-V_{E}$

$$
f_{R}(t)=\sqrt{5} \frac{C_{0}\left[V_{T}(t)-V_{E}\right]^{2}}{2 t_{\mathrm{ge}}} g^{\prime}\left(\frac{x_{P}(t)}{t_{\mathrm{ge}}}\right) .
$$

In the rms model, the loss, compliance and mass of the clamped plate are shown as a series $R L C$ section on the mechanical side

$$
\begin{aligned}
& C_{\mathrm{Rm}}=\frac{9}{5} \frac{\left(1-\sigma^{2}\right)}{16 \pi Y_{0}} \frac{a^{2}}{t_{m}^{3}} \\
& L_{\mathrm{Rm}}=\pi a^{2} \rho_{m} t_{m}
\end{aligned}
$$

where $Y_{0}, \sigma$, and $\rho$ are, respectively, Young's modulus, Poisson ratio, and density of the plate material. The frequency of fundamental mode resonance of clamped plate is referred to as mechanical resonance frequency $f_{m}$ and given as

$$
f_{m}=\frac{1}{2 \pi \sqrt{L_{\mathrm{Rm}} C_{\mathrm{Rm}}}}=\frac{1}{2 \pi} \frac{4}{3} \frac{t_{m}}{a^{2}} \sqrt{\frac{5 Y_{0}}{\left(1-\sigma^{2}\right) \rho_{m}}} .
$$

The difference between the static ambient pressure and the pressure in the gap causes a net static rms force $F_{\mathrm{Rb}}$ given as

$$
F_{\mathrm{Rb}}=\frac{\sqrt{5}}{3} \pi a^{2} P_{0}
$$

where $P_{0}$ represents the pressure difference. $f_{\mathrm{RI}}(t)=$ $2 \pi a^{2} p_{\text {in }}(t)$ is the incident force due to dynamic pressure $p_{\text {in }}(t)$, for a CMUT cell in rigid baffle.

\section{B. Small-Signal Equivalent Circuit}

The circuit parameters for small-signal charged CMUT rms model shown in Fig. 2(b) are given as [44]

$$
\begin{aligned}
n_{R} & =\sqrt{5} \frac{C_{0}\left(V_{\mathrm{dc}}-V_{E}\right)}{t_{\mathrm{ge}}} g^{\prime}\left(\frac{X_{P}}{t_{\mathrm{ge}}}\right) \\
& =\sqrt{\frac{4}{3} \frac{C_{0}}{C_{\mathrm{Rm}}}} \frac{V_{\mathrm{dc}}-V_{E}}{V_{r}} g^{\prime}\left(\frac{X_{P}}{t_{\mathrm{ge}}}\right)
\end{aligned}
$$


and the spring softening capacitance is

$$
\begin{aligned}
C_{\mathrm{RS}} & =\frac{2 t_{\mathrm{ge}}^{2}}{5 C_{0}\left(V_{\mathrm{dc}}-V_{E}\right)^{2} g^{\prime \prime}\left(X_{P} / t_{\mathrm{ge}}\right)} \\
& =C_{\mathrm{Rm}}\left[\frac{2}{3} \frac{\left(V_{\mathrm{dc}}-V_{E}\right)^{2}}{V_{r}^{2}} g^{\prime \prime}\left(\frac{X_{P}}{t_{\mathrm{ge}}}\right)\right]^{-1}
\end{aligned}
$$

where $g^{\prime \prime}(u)=\left(1 /(1-u)^{2}-3 g^{\prime}(u)\right) /(2 u)$ and the reference voltage $V_{r}$ is defined as the voltage that causes collapse in the absence of ambient static pressure

$$
\begin{aligned}
V_{r}=\sqrt{\frac{4 t_{\mathrm{ge}}^{2}}{3 C_{P m} C_{0}}} & =\sqrt{\frac{4 t_{\mathrm{ge}}^{2}}{15 C_{\mathrm{Rm}} C_{0}}} \\
& =8 t_{\mathrm{ge}} \frac{t_{m}^{2}}{a^{2}} \sqrt{\frac{t_{\mathrm{ge}}}{t_{m}}} \sqrt{\frac{Y_{0}}{27 \varepsilon_{0}\left(1-\sigma^{2}\right)}}
\end{aligned}
$$

and $C_{0 d}$ is the depressed capacitance of the CMUT cell

$$
C_{0 d}=C_{0} g\left(\frac{X_{P}}{t_{\mathrm{ge}}}\right) \text {. }
$$

$F_{\mathrm{Rg}}$ is the reference rms force required to deflect the plate until the central displacement reaches the effective gap height [44]

$$
F_{\mathrm{Rg}}=\frac{t_{\mathrm{ge}}}{\sqrt{5} C_{\mathrm{Rm}}}
$$

$F_{\mathrm{Rb}} / F_{\mathrm{Rg}}=F_{b} / F_{g}$ is the normalized static mechanical rms force acting on the plate [44]. $v(t)$ is the received small-signal ac voltage.

The collapse voltage $V_{C}$ is equal to $V_{r}$ in vacuum and decreases with increasing static ambient pressure. This dependence is approximated as [44]

$$
\begin{array}{r}
\frac{V_{C}}{V_{r}} \approx 0.9961-1.0468 \frac{F_{b}}{F_{g}}+0.06972\left(\frac{F_{b}}{F_{g}}-0.25\right)^{2} \\
+0.01148\left(\frac{F_{b}}{F_{g}}\right)^{6} .
\end{array}
$$

The resonance frequency of the series branch $f_{s}$ is an important parameter and given as

$$
f_{s}=\frac{1}{2 \pi \sqrt{L_{\mathrm{Rm}}\left(\frac{1}{C_{\mathrm{Rm}}}+\frac{1}{-C_{\mathrm{RS}}}\right)^{-1}}}
$$

in absence of the radiation reactance. The series resonance frequency can be expressed as

$$
f_{s}=f_{m} \sqrt{1-\frac{2}{3} \frac{V_{\mathrm{dc}}^{2}}{V_{r}^{2}} g^{\prime \prime}\left(\frac{X_{P}}{t_{\mathrm{ge}}}\right)}
$$

in terms of the mechanical resonance frequency.

\section{REFERENCES}

[1] X. Jin, I. Ladabaum, F. Degertekin, S. Calmes, and B. T. Khuri-Yakub, "Fabrication and characterization of surface micromachined capacitive ultrasonic immersion transducers," J. Microelectromech. Syst., vol. 8, no. 1, pp. 100-114, Mar. 1999.

[2] Y. Huang, E. O. Haeggstrom, X. Zhuang, A. S. Ergun, and B. T. Khuri-Yakub, "A solution to the charging problems in capacitive micromachined ultrasonic transducers," IEEE Trans. Ultrason., Ferroelect., Freq. Control, vol. 52, no. 4, pp. 578-580, Apr. 2005.

[3] K. Midtbø and A. Rønnekleiv, "Analysis of charge effects in high frequency CMUTs," in Proc. IEEE IUS, Nov. 2008, pp. 379-382.
[4] S. Machida et al., "Analysis of the charging problem in capacitive micro-machined ultrasonic transducers," in Proc. IEEE IUS, Nov. 2008, pp. 383-385.

[5] L. L. P. Wong, S. Na, A. I. H. Chen, and J. T. W. Yeow, "A novel method for measuring dielectric charging of CMUT arrays," in Proc. IEEE IUS, Sep. 2014, pp. 185-188.

[6] M.-C. Ho, M. Kupnik, K. K. Park, and B. T. Khuri-Yakub, "Longterm measurement results of pre-charged CMUTs with zero external bias operation," in Proc. IEEE IUS, Oct. 2012, pp. 89-92.

[7] G. Papaioannou and R. Plana, "Physics of charging in dielectrics and reliability of capacitive RF-MEMS switches," in Advanced Microwave and Millimeter Wave Technologies Semiconductor Devices Circuits and Systems, M. Mukherjee, Ed. Rijeka, Croatia: InTech, 2010, ch. 14 Accessed: Apr. 27, 2017. [Online]. Available: http://www.intechopen. com/books/advanced-microwave-and-millimeter-wave-technologiessemiconductor-devices-circuits-and-systems/physics-of-charging-indielectrics-and-reliability-of-capacitive-rf-mems-switches, doi: 10.5772/ 8747.

[8] R. Gerhard-Multhaupt, Electrets, vol. 2, 3rd ed. Morgan Hill, CA, USA Laplacian Press, 1998, pp. 9-12.

[9] M.-C. Ho, M. Kupnik, and B. T. Khuri-Yakub, "Pre-charged CMUTs for zero-external-bias operation," U.S. Patent 9242274 B2, Jan. 26, 2016.

[10] G. M. Sessler and J. E. West, "Self-biased condenser microphone with high capacitance," J. Acoust. Soc. Amer., vol. 34, no. 11, pp. 1787-1788, 1962.

[11] G. M. Sessler, "Electrostatic microphones with electret foil," J. Acoust. Soc. Amer, vol. 35, no. 9, pp. 1354-1357, 1963.

[12] D. Hohm and G. M. Sessler, "An integrated silicon-electret-condensor microphone," in Proc. 11th Int. Congr. Acoust., vol. 6. Paris, France, Jul. 1983, pp. 29-32.

[13] P. Günther, "Mechanism of charge storage in electron-beam or coronacharged silicon-dioxide electrets," IEEE Trans. Electr. Insul., vol. 24, no. 1, pp. 225-226, Feb. 1989.

[14] P. Günther and Z. Xia, "Transport of detrapped charges in thermally wet grown $\mathrm{SiO}_{2}$ electrets," J. Appl. Phys., vol. 74, no. 12, pp. 7269-7274, 1993.

[15] C. Thielemann, H. Amjadi, J. Klemberg-Sapieha, L. Martinu, and M. R. Wertheimer, "Miniaturized inorganic electret layers," in Proc. 8th Int. Symp. Electrets, Paris, France, Sep. 1994, pp. 1022-1027.

[16] H. C. Lai, P. Murphy, and M. Latour, "Improved silicon dioxide electret for silicon-based integrated microphones," in Proc. 8th Int. Symp. Electrets, Paris, France, Sep. 1994, pp. 949-950.

[17] H. Amjadi and C. Thielemann, "Silicon-based inorganic electrets for application in micromachined devices," IEEE Trans. Dielectr. Electr. Insul., vol. 3, no. 4, pp. 494-498, Aug. 1996.

[18] H. Amjadi, "Charge storage in double layers of silicon dioxide and silicon nitride," in Proc. 9th Int. Symp. Electrets, Shanghai, China, Sep. 1996, pp. 22-27.

[19] W. P. Mason, Electromechanical Transducers and Wave Filters. New York, NY: Van Nostrand, 1942.

[20] F. V. Hunt, Electroacoustics; the Analysis of Transduction, and Its Historical Background. Cambridge, U.K.: Harvard Univ. Press, 1954.

[21] J. E. Warren, "Capacitance microphone static membrane deflections: Comments and further results," J. Acoust. Soc. Amer., vol. 58, no. 3, pp. 733-740, 1975 .

[22] A. G. H. van der Donk, P. R. Scheeper, W. Olthuis, and P. Bergveld, "Modelling of silicon condenser microphones," Sens. Actuators A, Phys., vol. 40, no. 3, pp. 203-216, Mar. 1994.

[23] A. Bozkurt, I. Ladabaum, A. Atalar, and B. T. Khuri-Yakub, "Theory and analysis of electrode size optimization for capacitive microfabricated ultrasonic transducers," IEEE Trans. Ultrason., Ferroelect., Freq. Control, vol. 46, no. 6, pp. 1364-1374, Nov. 1999.

[24] G. G. Yaralioglu, A. S. Ergun, and B. T. Khuri-Yakub, "Finiteelement analysis of capacitive micromachined ultrasonic transducers," IEEE Trans. Ultrason., Ferroelect., Freq. Control, vol. 52, no. 12, pp. 2185-2198, Dec. 2002.

[25] S. P. Mao, X. Rottenberg, V. Rochus, B. Nauwelaers, and H. A. C. Tilmans, "FEM simulation and measurement validation of a cMUT cell," in Proc. 15th Int. Conf. Thermal, Mech. Multi-Phys. Simulation Experim. Microelectron. Microsyst. (EUROSIME), Apr. 2014, pp. $1-7$.

[26] S. Ballandras, M. Wilm, W. Daniau, A. Reinhardt, V. Laude, and R. Armati, "Periodic finite element/boundary element modeling of capacitive micromachined ultrasonic transducers," J. Appl. Phys., vol. 97, no. 3, pp. 034901-034907, 2005.

[27] M. Wilm, A. Reinhardt, V. Laude, R. Armati, W. Daniau, and S. Ballandras, "Three-dimensional modelling of micromachinedultrasonic-transducer arrays operating in water," Ultrasonics, vol. 43, no. 6, pp. 457-465, May 2005. 
[28] Y. Roh and B. T. Khuri-Yakub, "Finite element analysis of underwater capacitor micromachined ultrasonic transducers," IEEE Trans. Ultrason., Ferroelect., Freq. Control, vol. UFFC-49, no. 3, pp. 293-298, Mar. 2002.

[29] G. Wojcik, J. Mould, P. Reynolds, A. Fitzgerald, P. Wagner, and I. Ladabaum, "Time-domain models of MUT array cross-talk in silicon substrates," in Proc. IEEE Ultrason. Symp., Oct. 2000, pp. 909-914.

[30] G. G. Yaralioglu, B. Bayram, and B. T. Khuri-Yakub, "5F-3 finite element analysis of CMUTS: Conventional vs. collapse operation modes," in Proc. IEEE Ultrason. Symp., Vancouver, BC, Canada, Oct. 2006 pp. 586-589.

[31] B. Bayram et al., "Finite element modeling and experimental characterization of crosstalk in 1-D CMUT arrays," IEEE Trans. Ultrason. Ferroelect., Freq. Control, vol. 54, no. 2, pp. 418-430, Feb. 2007.

[32] A. Caronti, P. Gatta, C. Longo, A. S. Savoia, and M. Pappalardo, "A finite element tool for the analysis and the design of capacitive micromachined ultrasonic transducer (cMUT) arrays for medical imaging," J. Acoust. Soc. Amer., vol. 123, no. 5, p. 3375, 2008.

[33] I. O. Wygant et al., "Integration of 2D CMUT arrays with frontend electronics for volumetric ultrasound imaging," IEEE Trans. Ultrason., Ferroelect., Freq. Control, vol. 55, no. 2, pp. 327-342, Feb. 2008

[34] I. O. Wygant et al., "50 kHz capacitive micromachined ultrasonic transducers for generation of highly directional sound with parametric arrays," IEEE Trans. Ultrason., Ferroelect., Freq. Control, vol. 56, no. 1, pp. 193-203, Jan. 2009

[35] N. Apte, K. K. Park, and B. T. Khuri-Yakub, "Finite element analysis of CMUTs with pressurized cavities," in Proc. IEEE Ultrason. Symp., Dresden, Germany, Oct. 2012, pp. 979-982.

[36] D. Certon, F. Teston, and F. Patat, "A finite difference model for cMUT devices," IEEE Trans. Ultrason., Ferroelect., Freq. Control, vol. 52, no. 12, pp. 2199-2210, Dec. 2005.

[37] N. Sénégond, A. Boulmé, C. Plag, F. Teston, and D. Certon, "Fast timedomain modeling of fluid-coupled cMUT cells: From the single cell to the 1-D linear array element," IEEE Trans. Ultrason., Ferroelect., Freq. Control, vol. 60, no. 7, pp. 1505-1518, Jul. 2013.

[38] S. Satir and F. L. Degertekin, "A nonlinear lumped model for ultrasound systems using CMUT arrays," IEEE Trans. Ultrason., Ferroelect., Freq. Control, vol. 62, no. 10, pp. 1865-1879, Oct. 2015.

[39] A. Lohfink and P.-C. Eccardt, "Linear and nonlinear equivalent circuit modeling of CMUTs," IEEE Trans. Ultrason., Ferroelectr., Freq. Control, vol. 52, no. 12, pp. 2163-2172, Dec. 2005.

[40] I. O. Wygant, M. Kupnik, and B. T. Khuri-Yakub, "Analytically calculating membrane displacement and the equivalent circuit model of a circular CMUT cell," in Proc. IEEE Ultrason. Symp., Beijing, China, Nov. 2008, pp. 2111-2114.

[41] M. Rahman, J. Hernandez, and S. Chowdhury, "An improved analytical method to design CMUTs with square diaphragms," IEEE Trans. Ultrason., Ferroelect., Freq. Control, vol. 60, no. 4, pp. 834-845, Apr. 2013.

[42] M. F. la Cour, T. L. Christiansen, J. A. Jensen, and E. V. Thomsen, "Electrostatic and small-signal analysis of CMUTs with circular and square anisotropic plates," IEEE Trans. Ultrason., Ferroelect., Freq. Control, vol. 62, no. 8, pp. 1563-1579, Aug. 2015.

[43] A. Caronti, G. Caliano, A. Iula, and M. Pappalardo, "An accurate model for capacitive micromachined ultrasonic transducers," IEEE Trans. Ultrason., Ferroelect., Freq. Control, vol. 49, no. 2 , pp. 159-168, Feb. 2002.

[44] H. Koymen et al., "An improved lumped element nonlinear circuit model for a circular CMUT cell," IEEE Trans. Ultrason., Ferroelect., Freq. Control, vol. 59, no. 8, pp. 1791-1799, Aug. 2012.

[45] H. K. Oğuz, A. Atalar, and H. Köymen, "Equivalent circuit-based analysis of CMUT cell dynamics in arrays," IEEE Trans. Ultrason., Ferroelect., Freq. Control, vol. 60, no. 5, pp. 1016-1024, May 2013

[46] G. M. Sessler, "Electric fields and forces due to charged dielectrics," J. Acoust. Soc. Amer., vol. 43, no. 2, pp. 405-408, 1972.

[47] G. M. Sessler, Electrets, vol. 1, 3rd ed. Morgan Hill, CA, USA Laplacian Press, 1998, pp. 13-18.

[48] T. Mellow and L. Kärkkäinen, "On the forces in single-ended and push-pull electret transducers," J. Acoust. Soc. Amer., vol. 124, no. 3, pp. 1497-1504, 2008

[49] E. Ventsel and T. Krauthammer, Thin Plates and Shells: Theory: Analysis, and Applications. New York, NY, USA: Dekker, 2001.

[50] A. Unlugedik, A. S. Tasdelen, A. Atalar, and H. Koymen, "Designing transmitting CMUT cells for airborne applications," IEEE Trans. Ultrason., Ferroelect., Freq. Control, vol. 61, no. 11, pp. 1899-1910, Nov. 2014

[51] Condenser Microphones and Microphone Preamplifiers for Acoustic Measurement, Data Handbook, Bruel and Kjær, Nærum, Denmark, 1982.
[52] H. Köymen, A. Atalar, and A. S. Taşdelen, "Bilateral CMUT cells and arrays: Equivalent circuits, diffraction constants, and substrate impedance," IEEE Trans. Ultrason., Ferroelect., Freq. Control, vol. 64, no. 2, pp. 414-423, Feb. 2017.

[53] H. Köymen, A. Atalar, and H. K. Oğuz, "Designing circular CMUT cells using CMUT biasing chart," in Proc. IEEE Int. Ultrason. Symp., Dresden, Germany, Oct. 2012, pp. 975-978.

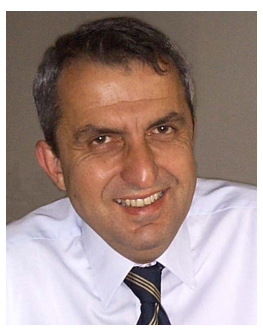

Hayrettin Köymen (M'76-SM'91) received the B.Sc. and M.Sc. degrees in electrical engineering from Middle East Technical University (METU), Ankara, Turkey, in 1973 and 1976, respectively, and the Ph.D. degree in electrical engineering from Birmingham University, Birmingham, U.K., in 1979 .

From 1979 to 1990, he was with the Department of Marine Sciences, METU, Mersin, Turkey, and with the Department of Electrical Engineering, METU, Ankara. In 1990, he joined the faculty of Bilkent University, Ankara, where he is currently a Professor with the Department of Electrical and Electronics Engineering. His research interests include underwater and airborne acoustic and ultrasonic transducer design, underwater acoustics, underwater and airborne acoustic systems, acoustic microscopy, ultrasonic NDT, biomedical instrumentation, mobile communications, and spectrum management.

Prof. Köymen is an IET Fellow.

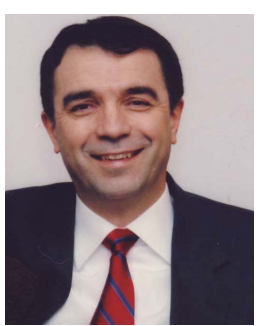

Abdullah Atalar (M'88-SM'90-F'07) received the B.S. degree in electrical engineering from Middle East Technical University (METU), Ankara, Turkey, in 1974, and the M.S. and Ph.D. degrees in electrical engineering from Stanford University, Stanford, CA USA, in 1976 and 1978, respectively.

In 1979, he was with Hewlett-Packard Laboratories, Palo Alto, CA, USA. From 1980 to 1986, he was an Assistant Professor with METU. In 1986, he was a Chairman with the Department of Electrical and Electronics Engineering, Bilkent University, Ankara, and participated in founding the department. In 1995, he was a Visiting Professor with Stanford University. From 1996 to 2010, he was the Provost with Bilkent University, where he is currently the Rector and a Professor. His current research interests include micromachined devices and microwave electronics.

Dr. Atalar is a member of the Turkish Academy of Sciences. He was a recipient of the TUBITAK Science Award in 1994.

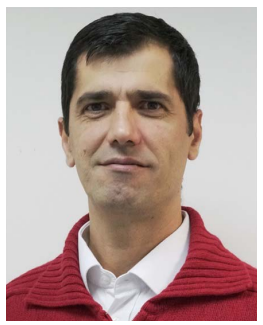

Saadettin Güler was born in İmir, Turkey, in 1974. He received the B.S. and M.S. degrees in electrical and electronics engineering from Bilkent University, Ankara, Turkey, in 1996 and 2004, respectively, and the $\mathrm{Ph} . \mathrm{D}$. degree in electronics engineering from Ankara University, Ankara, in 2011.

From 1996 to 2012, he was with the Bilkent University Computer Center, Havelsan and A-tel, Ankara, sequentially. Since 2012, he has been a Research Engineer with the Bilkent University Acoustics and Underwater Technologies Research Center. His research interests include speech processing, signal processing, underwater acoustics, and biomedical ultrasound.

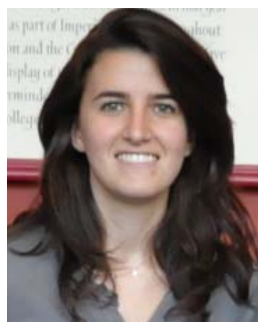

Itır Köymen was born in Ankara, Turkey, in 1987. She received the M.Eng. degree (Hons.) in electronics and electrical engineering from The University of Edinburgh, Edinburgh, U.K., in 2010, and the Ph.D. degree in bioengineering from Imperial College London, London, U.K., in 2014.

She is currently a TUBITAK Post-Doctoral Fellow at Bilkent University, Ankara. Her research interests include fabrication, characterization, the modeling and applications of micro-nanometric nonlinear devices, and analog circuits for and inspired by biology. 


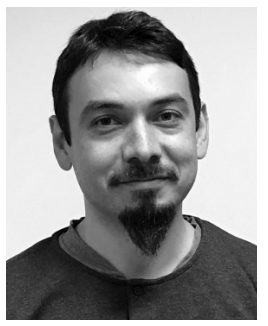

A. Sinan Taşdelen was born in Ankara, Turkey, in 1981. He received the B.S. and M.S. degrees in electrical and electronics engineering from Bilkent University, Ankara, in 2004 and 2007, respectively. In 2008, he joined the Bilkent University Acoustics and Underwater Technologies Research Center, where he is currently a Chief Technical Research Engineer. His research interests include passive coherent location radar, underwater acoustics, transducer array design, and biomedical ultrasound.

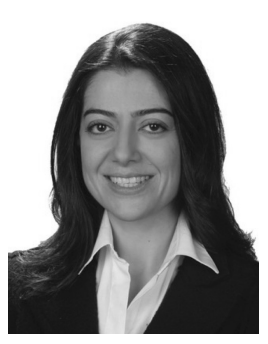

Aslı Ünlügedik received the B.Sc. degree in electrical and electronics engineering from Yeditepe University, Istanbul, Turkey, in 2004, the M.Sc. degree in electronics and communication engineering from Istanbul Technical University, Istanbul, in 2007, and the $\mathrm{Ph} . \mathrm{D}$. degree from the Department of Electrical and Electronics Engineering, Bilkent University, Ankara, Turkey, in 2014

She was a Post-Doctoral Fellow at the E. L. Ginzton Laboratory, Stanford University, Stanford, CA, USA, from 2014 to 2015. She currently holds a postdoctoral position with the Mechanical Engineering Department, University of Texas at Austin, Austin, TX, USA. Her research interests include the design, characterization, and fabrication of CMUTs. 